\title{
PERSEPSI PEMANFAATAN PETA DAERAH PENANGKAPAN IKAN DI PERAIRAN SENDANG BIRU MALANG
}

\author{
Perception of The Use of Fishing Ground Map in Sendang Biru Waters Malang
}

Oleh:

Onesimus Dhyas Dwi Atmajaya ${ }^{1 *}$, Domu Simbolon², Budy Wiryawan²

${ }^{1}$ Mahasiswa Program Studi Teknologi Perikanan Laut

${ }^{2}$ Staf Pengajar Program Studi Teknologi Perikanan Laut

*Korespondensi: onesinginkaya@gmail.com

\begin{abstract}
ABSTRAK
Perairan Sendang Biru merupakan perairan yang sangat potensial sebagai daerah penangkapan ikan di Pantai Selatan Jawa, lokasi yang berbatasan langsung dengan Samudera Hindia memungkinkan terjadinya masukan-masukan ikan dari perairan bebas sehingga menambah keanekaragaman jenis ikan yang ditangkap. Berdasarkan informasi yang diperoleh dari DKP Kabupaten Malang (2013) produksi perikanan di Sendang Biru terus meningkat dari tahun ke tahun, dimana pada tahun 2010 produksi perikanan tercatat 9600 ton dan meningkat menjadi 10566 ton pada tahun 2013, dan diprediksi akan terus mengalami peningkatan sekitar $5 \%$ pertahun. Tujuan dari penelitian ini adalah untuk mengetahui persepsi para aktor dan agen mengenai informasi pemanfaatan peta perencanaan daerah penangkapan ikan (PPDPI) yang dibuat oleh Balai Penelitian dan Observasi Laut(BPOL). Para aktor berpendapat bahwa PPDPI masih belum terlalu penting, maka dari itu perlu adanya pendekatan secara insentif dari agen dalam pengelolaan perikanan secara berkelanjutan menggunakan PPDPI.
\end{abstract}

Kata kunci: informasi, insentif, persepsi, daerah penangkapan ikan, aktor, agen.

\begin{abstract}
Sendang Biru waters is one of potential fishing ground in South Coast of Java, located of adjacent to the Indian Ocean allows that lot of fish resources. According to information obtained from the DKP Malang (2013), Sendang Biru fisheries production continued to increase over the years, where in 2010 the fishery production recorded 9600 tons and increased to 10566 tons in 2013, and is predicted to constantly increasing approximately 5\% per year. The purpose of this study was to determine the perception of the actors and agents about the use of information in spatial planning maps of the fishing ground (PPDPI) provided by Marine and Fisheries Observation Institute (BPOL). The actors found $P P D P I$ still have not too important, and therefore there needs to be an incentive approach of the agents in the using PPDPI.
\end{abstract}

Keywords: information, incentive, perception, fishing ground, actors, agents.

\section{PENDAHULUAN}

Malang Selatan adalah daerah yang memiliki potensi perikanan yang sangat besar. Potensi perikanan yang besar menjadi prioritas Pemerintah Kabupaten Malang dalam upaya meningkatkan kegiatan perekonomian di sektor kelautan (Hermawan 2011). Potensi perikanan laut di Kabupaten Malang berada di sepanjang pantai $102 \mathrm{~km}$ membentang mulai Kecamatan Ampelgading, Sumbermanjing Wetan hingga Gedangan. (DKP Malang 2015). Produksi perikanan di Kabupaten Malang diprediksi terus meningkat setiap tahunnya. Peningkatan produksi perikanan tangkap 
didukung oleh peningkatan kualitas sumberdaya manusia, peningkatan kualitas teknologi perikanan dan sarana prasarana yang memadai (DKP Malang 2016). Informasi mengenai peta daerah penangkapan ikan merupakan upaya untuk meningkatkan kualitas teknologi perikanan dalam pengelolaan sumberdaya perikanan. Peta perencanaan daerah penangkapan ikan (PPDPI) adalah salah satu cara yang diharapkan dapat membantu nelayan dalam menentukan lokasi daerah penangkapan ikan (DPI) untuk mendapatkan hasil tangkapan yang optimal (BPOL 2007). PPDPI masih belum dapat digunakan secara optimal oleh nelayan di Sendang Biru oleh karena itu perlu dilakukan beberapa kajian untuk menganalisis faktor-faktor yang berpengaruh bagi nelayan dalam memanfatkan PPDPI. Kajian yang dapat dilakukan adalah dengan cara menganalisis persepsi mengenai pemanfaatan PPDPI dengan melibatkan agen dan aktor yang terlibat dalam pemanfaatan PPDPI. Tujuan dari penelitian ini adalah untuk mengetahui persepsi para aktor yaitu nelayan dan agen yaitu lembaga pemerintah mengenai informasi PPDPI.

\section{METODE PENELITIAN}

Penelitian ini dilaksanakan di Pelabuhan Perikanan Pantai Pondokdadap Sendang Biru Desa Tambakrejo, Kecamatan Sumbermanjing Wetan, Kabupaten Malang. Kegiatan penelitian ini dilaksanakan pada bulan Maret 2016. Data yang digunakan dalam penelitian ini adalah data primer. Data bersumber dari kelompok aktor dan kelompok agen. Kelompok aktor terdiri dari nelayan jaring lingkar dan nelayan pancing ulur. Kelompok aktor dan kelompok agen yang digunakan sebagai responden ditentukan secara purposive sampling (sengaja) sebanyak 30 sampel. Data yang dibutuhkan yaitu persepsi agen dan aktor mengenai PPDPI berdasarkan aspek ekologi dan teknologi dan persepsi aktor mengenai PPDPI berdasarkan aspek sosial dan lingkungan. Menurut Bailey et al. (2015) Dalam upaya mengelola perikanan tuna yang ber-kelanjutan perlu adanya intesivitas (dorongan/motivasi) dari pemerintah atau lembaga perikanan selaku agen kepada nelayan selaku aktor dalam upaya pengembangan perikanan tangkap. Pengumpulan data penelitian dari responden meliputi aspek ekologi, teknologi, sosial dan lingkungan.

Data dianalisis secara deskriptif dengan skala likert. Skala likert adalah suatu skala psikometrik yang umum digunakan dalam kuesioner dan merupakan skala yang paling banyak digunakan dalam riset berupa survei (Natzir 2005). Contoh penggunaan skala likert pada aspek ekologi disajikan pada Tabel 1.

Tabel 1 Skala likert dalam penentuan persepsi nelayan dalam memanfaatkan PPDPI berdasarkan aspek ekologi

\begin{tabular}{ccc}
\hline Variabel & Kategori & Skala \\
\hline \multirow{3}{*}{ Jumlah ikan } & Meningkat & 3 \\
& Tetap & 2 \\
& Menurun & 1 \\
\hline \multirow{3}{*}{ Keragaman ikan } & Meningkat & 3 \\
& Tetap & 2 \\
& Tidak tahu & 1 \\
\hline \multirow{2}{*}{ Penyebaran SDI } & Semakin luas & 3 \\
& Tetap & 2 \\
& Tidak tahu & 1 \\
\hline
\end{tabular}

Hasil analisis skala likert selanjutnya dianalisis menggunakan perceptual map. Perceptual map digunakan untuk mengelompokan stakholder apakah memiliki persepsi yang sama atau berbeda (Ross, 2011). Perceptual map digambarkan dalam bentuk diagram kartesius (Gambar 1). 


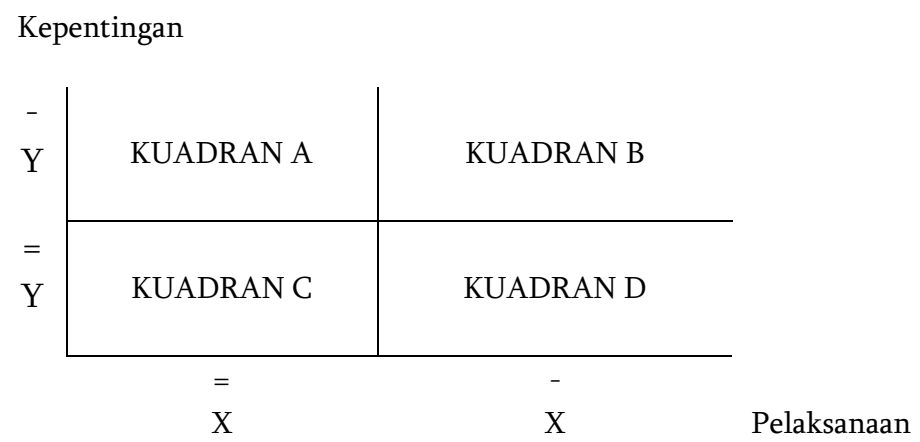

Gambar 1 Diagram kartesius perceptual map

Keterangan :

A. menunjukan faktor atau atribut yang dianggap mempengaruhi pengetahuan nelayan tentang informasi PPDPI, dimana faktor tersebut dianggap penting tetapi belum dilaksanakan oleh nelayan

B. menunjukan faktor-faktor penting yang mempengaruhi pengetahuan nelayan tentang informasi PPDPI, dan sudah dilaksanakan oleh nelayan sehingga wajib dipertahankan

C. menunjukan faktor yang kurang berpengaruh terhadap pengetahuan nelayan tentang informasi PPDPI, maka nelayan tidak wajib melaksanakannya

D. menunjukan faktor-faktor yang kurang berpengaruh terhadap pengetahuan nelayan tentang informasi PPDPI, tetapi telah dilaksanakan oleh nelayan, sehingga hal ini dianggap berlebihan.

\section{HASIL DAN PEMBAHASAN}

\section{Persepsi pemanfaatan PPDPI berdasarkan aspek ekologi}

Persepsi pemanfaatan PPDPI berdasarkan aspek ekologi dapat dilihat pada Tabel 2.

Tabel 2 Persepsi pemanfaatan PPDPI berdasarkan aspek ekologi

\begin{tabular}{llcccc}
\hline \multirow{2}{*}{ Variabel } & \multirow{2}{*}{ Kategori } & \multicolumn{3}{c}{ Aktor } & \multicolumn{2}{c}{ Agen } \\
\cline { 3 - 6 } & & 50 & 50 & 60 & 60 \\
\cline { 3 - 6 } Perkembangan & Meningkat & N. Jaring lingkar & N. Pancing ulur & Pegawai & Pengawas \\
jumlah ikan yang & Tetap & 40 & 40 & 20 & 20 \\
didaratkan & Menurun & 10 & 10 & 20 & 20 \\
\hline \multirow{3}{*}{ Keragaman ikan } & Meningkat & 50 & 30 & 60 & 40 \\
& Tetap & 10 & 40 & 20 & 0 \\
& Tidak tahu & 40 & 30 & 20 & 60 \\
\hline \multirow{3}{*}{ Penyebaran SDI } & Semakin & & & & \\
& luas & 40 & 40 & 60 & 20 \\
& Tetap & 40 & 20 & 20 & 60 \\
& Dibatasi & 20 & 40 & 20 & 20 \\
\hline
\end{tabular}

Persepsi responden yang paling dominan pada variabel perkembangan jumlah ikan yang didaratkan yaitu sebanyak $50 \%$ responden aktor dan $60 \%$ responden agen menyatakan ikan yang didaratkan selalu mengalami peningkatan. Pada variabel keragaman ikan sebanyak $50 \%$ responden nelayan jaring lingkar dan $60 \%$ responden pegawai menyatakan keragaman ikan selalu mengalami peningkatan. Pada variabel penyebaran SDI sebanyak $60 \%$ responden pegawai menyatakan penyebaran ikan di Sendang Biru semakin luas. Hasil dari persepsi yang telah disampaikan oleh para agen dan aktor, kemudian dapat dipetakan ke dalam peta perseptual sebagaimana disajikan pada Gambar 2. 


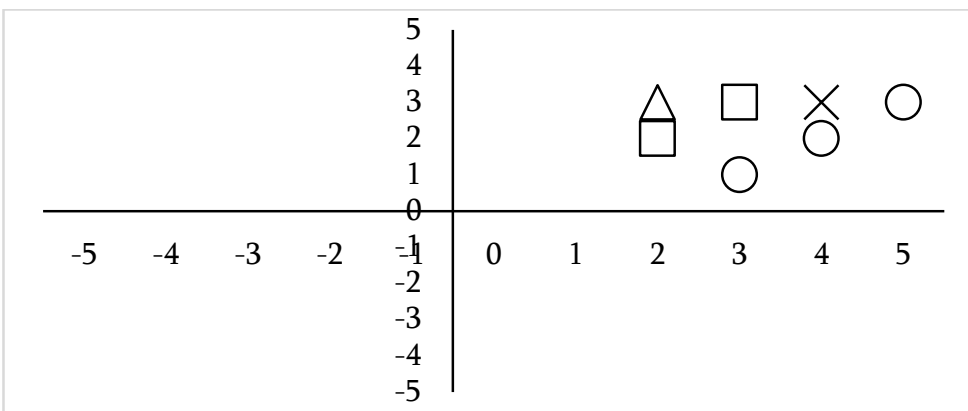

$\Delta$ N. Jaring Lingkar $\square$ N. Pancing Ulur $\times$ Pegawai $O$ Pengawas

Gambar 2 Peta perseptual pemanfaatan PDPI berdasarkan aspek ekologi

Pada Gambar 2, secara aspek ekologi, pengelolaan sumberdaya perikanan laut di Sendang Biru sudah dilakukan oleh para aktor dan agen dengan baik sehingga perlu dipertahankan agar PPDPI dapat dimanfaatkan secara optimal (Kuadran A). Badjeck et al. (2010) menambahkan bahwa perubahan ekologis yang terjadi di laut dapat menyebabkan ketersediaan produksi perikanan mengalami perubahan. Dalam hal ini agen berperan mengelola dan mengatur para aktor agar dapat memanfaatkan PPDPI secara optimal

\section{Persepsi pemanfaatan PPDPI berdasarkan aspek tekologi}

Persepsi pemanfaatan PPDPI berdasarkan aspek tekologi dapat dilihat pada Tabel 3

Tabel 3 Persepsi pemanfaatan PPDPI berdasarkan aspek teknologi

\begin{tabular}{lllccc}
\hline \multirow{2}{*}{ Variabel } & \multirow{2}{*}{ Kategori } & \multicolumn{3}{c}{ Aktor } & \multicolumn{2}{c}{ Agen } \\
\cline { 3 - 6 } & & & \multicolumn{3}{c}{ Responden (\%) } \\
\cline { 3 - 6 } & S. Jaring lingkar & N. Pancing ulur & Pegawai & Pengawas \\
\hline Kemampuan & mahir & 20 & 70 & 40 & 80 \\
nelayan dalam & Mahir & 40 & 20 & 0 & 20 \\
memanfaatkan & Sebatas bisa & 40 & 10 & 60 & 0 \\
teknologi & Berkembang & 70 & 70 & 0 & 60 \\
\hline \multirow{2}{*}{ Perkembangan } & Tetap & 20 & 10 & 40 & 20 \\
teknologi & Tidak tahu & 10 & 20 & 60 & 20 \\
& Ya & 20 & 10 & 60 & 40 \\
Peta BPOL sebagai & Tidak & 50 & 60 & 40 & 60 \\
acuan penentuan & Tidak tahu & 30 & 30 & 0 & 0 \\
DPI & & &
\end{tabular}

Persepsi responden yang paling dominan pada variabel kemampuan nelayan dalam memanfaatkan teknologi yaitu sebanyak $70 \%$ responden nelayan pancing ulur dan $80 \%$ responden pengawas menyatakan sangat mahir. Pada variabel perkembangan teknologi sebanyak $70 \%$ responden aktor menyatakan teknologi perikanan di PPP Pondokdadap selalu berkembang. Pada variabel peta BPOL sebagai acuan penentuan DPI sebanyak $60 \%$ responden pegawai menyatakan peta BPOL dapat digunakan sebagai acuan penentuan DPI. Hasil dari persepsi pemanfaatan PDPI berdasarkan aspek teknologi selanjutnya dipetakan dengan peta perseptual pada Gambar 3. 


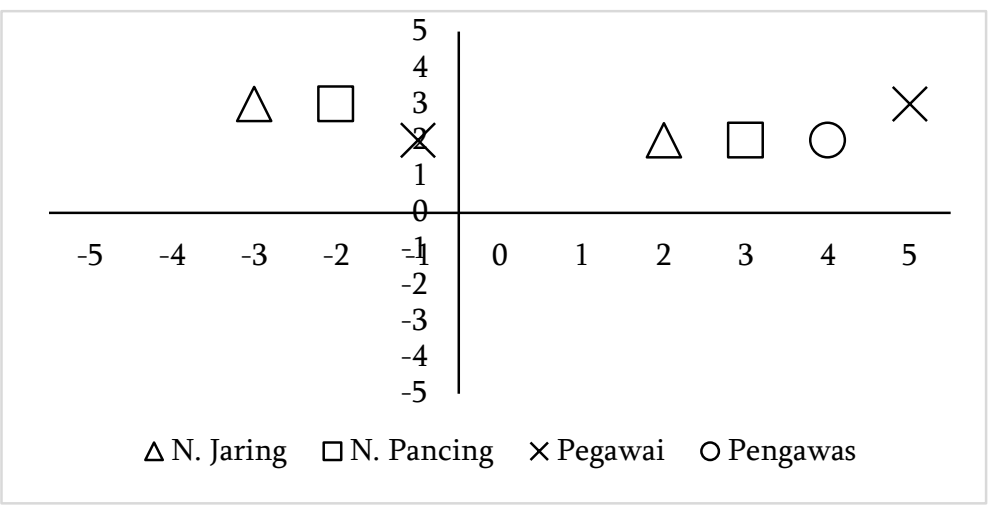

Gambar 3 Peta Perseptual pemanfaatan PDPI berdasarkan aspek teknologi

Pada Gambar 3, secara aspek sosial pegawai selaku agen masuk ke dalam Kuadran A dan Kuadran B, dimana pegawai sudah menggunakan peta PDPI dan selalu menerapkan peta PDPI untuk pengelolaan perikanan laut (Kuadran B), tetapi belum menerapkan kepada nelayan secara baik (Kuadran A). Mardle \& Pascoe (2002), menyatakan bahwa, pemerintah sebagai agen dan juga pemilik informasi mengenai sumber daya perikanan, sering memiliki informasi yang tidak sempurna, yang dapat menyebabkan munculnya masalah yang sangat prinsip. Bailey et al. (2015) menambahkan, dalam upaya mengelola sumberdaya perikanan yang berkelanjutan maka perlu adanya pendekatan yang insentif, namun pada kenyataannya sering terjadi kesenjangan insentif antara pemerintah selaku agen dan nelayan selaku aktor sehingga sering terjadi bahaya moral pada pelaku perikanan. Peran agen yaitu mengarahkan para aktor agar tidak hanya terpacu pada alat bantu penangkapan ikan tetapi juga memanfaatkan peta PDPI untuk perikanan yang berkelanjutan secara lebih insentif.

\section{Persepsi pemanfaatan PPDPI berdasarkan aspek sosial}

Persepsi pemanfaatan PPDPI berdasarkan aspek sosial dapat dilihat pada Tabel 4.

Tabel 4 Persepsi pemanfaatan PPDPI berdasarkan aspek sosial

\begin{tabular}{llcc}
\hline \multirow{2}{*}{ Variabel } & \multirow{2}{*}{ Kategori } & \multicolumn{2}{c}{ Responden Aktor (\%) } \\
\cline { 3 - 4 } & & N. Jaring lingkar & N. Pancing ulur \\
\hline \multirow{3}{*}{ Jumlah nelayan } & Meningkat & 90 & 40 \\
& Tetap & 10 & 30 \\
& Tidak tahu & 0 & 30 \\
\hline \multirow{3}{*}{ Status pendidikan } & $<$ SD & 30 & 70 \\
& SMP & 50 & 30 \\
& $>$ SMA & 20 & 0 \\
\hline \multirow{2}{*}{ Usia } & $>30$ & 40 & 40 \\
& $20-30$ & 60 & 60 \\
& $<20$ & 0 & 0 \\
\hline
\end{tabular}

Persepsi responden yang paling dominan pada variabel jumlah nelayan yaitu sebanyak $90 \%$ nelayan jaring lingkar menyatakan jumlah nelayan di PPP Pondokdadap selalu meningkat. Sebanyak $70 \%$ responden nelayan pancing ulur menyatakan rata-rata nelayan adalah nelayan berpendidikan SD. Sebanyak 60 \% responden aktor menyatakan usia nelayan PPP Pondokdadap mayoritas berusia 20 -30 tahun. Hasil dari persepsi pemanfaatan PDPI berdasarkan aspek sosial selanjutnya dipetakan dengan peta perseptual pada Gambar 4. 


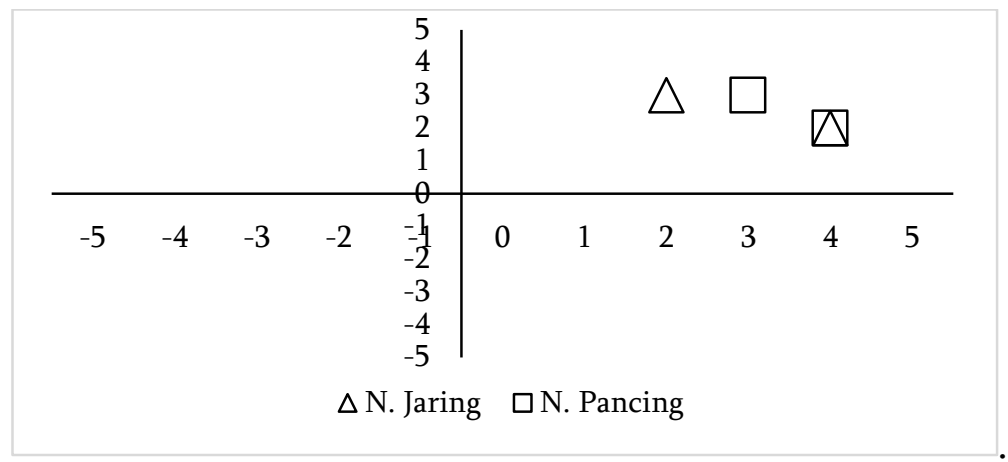

Gambar 4 Peta perseptual pemanfaatan PDPI berdasarkan aspek sosial

Pada Gambar 4, aspek sosial sangat berpengaruh terhadap kegiatan operasional penangkapan ikan sehingga kegiatan penangkapan ikan di Sendangbiru tetap terus berjalan dengan baik dan harus tetap dipertahankan agar untuk kedepannya nelayan mampu untuk memanfaatkan PPDPI secara optimal (Kuadran B). Rachman (2013) melaporkan bahwa banyak nelayan di Sendangbiru tidak terlalu mengutamakan pendidikan untuk melakukan kegiatan melaut sehingga banyak diantara nelayan yang berpendidikan tidak lulus SD - tamat SD dengan rata-rata usia 18-30 tahun. Papalia (2008) menambahkan, sebelum usia 30 tahun pancar indera manusia masih berfungsi dengan baik sehingga dapat dengan mudah untuk menerima segala rangsangan/informasi yang didapat. Di usia produktif nelayan agen dapat dengan mudah melakukan sosialisasi terhadap nelayan mengenai PPDPI secara insentif.

\section{Persepsi pemanfaatan PPDPI berdasarkan aspek lingkungan}

Persepsi pemanfaatan PPDPI berdasarkan aspek lingkungan dapat dilihat pada Tabel 5.

Tabel 5 Persepsi pemanfaatan PPDPI berdasarkan aspek lingkungan

\begin{tabular}{llcc}
\hline \multirow{2}{*}{ Variabel } & \multirow{2}{*}{ Kategori } & \multicolumn{2}{c}{ Responden Aktor (\%) } \\
\cline { 3 - 4 } & & N. Jaring limgkar & N. Pancing ulur \\
\hline Kendala pada saat & Angin & 40 & 20 \\
melakukan kegiatan & Gelombang & 50 & 60 \\
menangkap ikan & Kendala lain & 10 & 20 \\
\hline Faktor penentu & Keberuntungan & 50 & 50 \\
keberhasilan & Musim & 30 & 40 \\
menangkap ikan & Faktor lain & 20 & 10 \\
\hline Perlunya informasi & Perlu & 40 & 40 \\
mengenai kondisi & Tidak perlu & 60 & 30 \\
perairan di DPI & Tidak tahu & 0 & 30 \\
\hline
\end{tabular}

Persepsi responden yang paling dominan pada variabel kendala pada saat kegiatan penangkapan ikan yaitu sebanyak $60 \%$ responden nelayan pancing ulur menyatakan bahwa gelombang adalah kendala yang paling berpengaruh terhadap kegiatan penangkapan ikan. Sebanyak $50 \%$ responden aktor menyatakan bahwa faktor keberuntungan adalah faktor yang paling berpengaruh pada keberhasilan menangkap ikan. Sebanyak $40 \%$ responden nelayan pancing ulur menyatakan bahwa dalam melakukan kegiatan penangkapan ikan perlu adanya informasi mengenai kondisi perairan di DPI. Hasil dari persepsi pemanfaatan PDPI berdasarkan aspek lingkungan selanjutnya dipetakan dengan peta perseptual pada Gambar 5. 


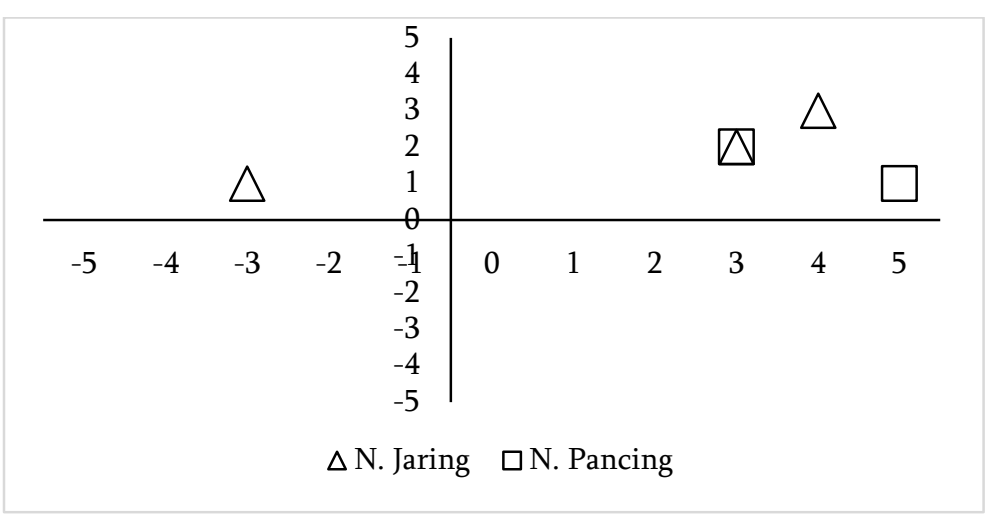

Gambar 5 Peta perseptual pemanfaatan PDPI berdasarkan aspek lingkungan

Gambar 5 menunjukan bahwa nelayan pancing ulur dan nelayan jaring lingkar sama-sama mampu mengatasi gelombang ketika melakukan operasi penangkapan ikan, sehingga harus dipertahankan (Kuadran B). Nelayan pancing memerlukan informasi mengenai kondisi perairan Sendang Biru untuk kegiatan penangkapan ikan yang lebih optimal (Kuadran B). Nelayan jaring tidak terlalu memerlukan informasi mengenai kondisi perairan tetapi lebih membutuhkan sarana lain untuk kegiatan penangkapan ikan yang lebih optimal.

\section{KESIMPULAN DAN SARAN}

Berdasarkan analisis yang dilakukan dalam penelitian ini, maka dapat disimpulkan bahwa pegawai selaku agen menilai pemanfaatan peta pemanfaatan daerah penangkapan ikan (PPDPI) penting sebagai acuan untuk pengelolaan DPI yang berkelanjutan, namun nelayan selaku aktor menilai PPDPI belum terlalu penting Adapun saran dari peneliti adalah agar para agen yaitu pegawai selaku agen dapat melakukan sosialisasi yang lebih insentif kepada para aktor yaitu nelayan agar dapat memanfaatkan PPDPI secara optimum untuk perikanan yang berkelanjutan.

\section{DAFTAR PUSTAKA}

Badjeck MC, Allison EH, Halls AS, Dulvy NK. 2010. Impacts of climate variability and change on fishery-based livelihoods. Marine Policy. 34:374-383.

Bailey M, Miller AMM, Bush SR, Zweiten PAM, Wiryawan B. 2015. Closing the incentive gap: the role of public and private actors in Governing Indonesia's tuna fisheries. Journal of Environmental Policy \& Planning. 18(2): 141-160.

[BPOL] Balai Penelitian dan Observasi Laut. 2007. Panduan Membaca Peta Prakiraan Daerah Penangkapan Ikan. Bali.(ID): BPOL. 8 hlm.

[DKP] Dinas Kelautan dan Perikanan Kabupaten Malang. 2013. Buku Laporan Statistik. Malang (ID): DKP Malang. Jawa Timur. $58 \mathrm{hlm}$.

[DKP] Dinas Kelautan dan Perikanan Kabupaten Malang. 2015. Rencana Strategis Dinas Kelautan dan Perikan Kabupaten Malang. Malang (ID): DKP Malang. Jawa Timur. 62 hlm.

[DKP] Dinas Kelautan dan Perikanan Kabupaten Malang. 2015. Rencana Kerja Dinas Kelautan dan Perikan Kabupaten Malang. Malang (ID): DKP Malang. Jawa Timur. 68 hlm.

Hermawan D. 2011. Desain pengelolaan perikanan madidihang (Thunnus albacores) di perairan ZEEI Samudera Hindia Selatan Jawa Timur [disertasi]. Bogor (ID): Institut Pertanian Bogor. 239 hlm. 
Malhotra, Naresh K. 1999. Marketing Research: An Applied Orientation, Third Edition. New Jersey (US): Prentice Hall International Inc. $62 \mathrm{hlm}$.

Mardle S, Pascoe S. 2002. Modelling the effects of trade-offs between long and short term objectives in fisheries management. Journal of Environmental Management. 65(1):49-62. doi:10.1006/jema.2001.0518.

Nazir, Moh. 2005. Metode Penelitian. Jakarta (ID): Ghalia Indonesia. $622 \mathrm{hlm}$.

Papalia D. 2008. Human Development. Jakarta (ID). Kencana Prenada Mediagroup. 676 hlm.

Rahman, A. 2013. Perilaku ekonomi nelayan ikan tuna dalam kerangka industrialisasi perikanan. [skripsi]. Bogor (ID). Institut Pertanian Bogor. 119 hlm.

Ross A, Wiyono ES, Nurani TW. 2012. Persepsi sosial stakeholder perikanan tangkap di Prigi, Trenggalek. Buletin PSP. 20(3):229-237. 